\title{
Behn's The Emperor of the Moon in 2020
}

\author{
Misty G. Anderson
}

When the gifted actors Charles Pasternak and Charlotte Munson first brought the idea of a Zoom production of Aphra Behn's The Emperor of the Moon to me, I admit I was wary. While I was longing to have another chance to collaborate with them after our delightful (and sold-out) 2017 production of Susannah Centlivre's The Busy Body at the Clarence Brown Theatre, and while I'm not afraid of Zoom readings, Emperor seemed, well, dangerous. Could we manage the physical, even acrobatic elements of this commedia farce and its spectacle-filled conclusion, with the expensive machinery from John Dryden's opera Albion and Albanius written into the plot in the United Company's 1687 prop recycling plan? Could we also deliver inside political jokes that even a scholarly audience might strain to track? And could we provide live music and enlist a big cast with no budget? This would be a risky business indeed.

The three of us talked and edited in several rounds over the summer. Then the luminous Carol Mayo Jenkins joined us for a read-through, and the revelations began. Zoom could be our friend, with its humble "share screen" function allowing us to recycle images and wink at our own circumstances, technological and political, with joyous, silly abandon. The risk of farce, always foregrounding the risk at the heart of physical comedy, (that experience of what Bergson called "the mechanical encrusted on the living") became the technological risk of bodies falling or disappearing through the airwaves in a me- dium known for freezes and crashes. And while we did not advertise this to the audience, this reading was the first time all of the actors had been together for what was a thoughtfully proposed and planned but barely rehearsed reading, albeit with an absurdly talented bunch.

Pasternak, the Artistic Director of Porters of Hellsgate (Los Angeles, CA), first came to my attention as Saturninus in Shakespeare's Titus Andronicus and then as the delightfully oblivious Marplot in The Busy Body. Torn, like Garrick, between the muses of tragedy and comedy, part of Pasternak's genius is the seriousness with which he takes clowning. His fierce intelligence undergirds the verbal dexterity that Restoration and eighteenth-century work demands of actors, who must think and speak in Ciceronian paragraphs. Pasternak, Munson, and Brittany Pirizzoli all worked with the director John Sipes, who bears no part of the blame for our shameless venture here. Naming his hidden influence might seem quite the contradiction, given his own meticulous practice as a movement director grounded by Kabuki, Lecoq, and Copeau-based training. But this lineage, which runs back through Goldoni and even earlier clowning and commedia traditions, makes him a steward of Restoration and eighteenth-century kinetic knowledge. We have all been the beneficiaries of that embodied archive of knowledge through working with him.

Our revision cut several parts (the twelve persons of the Zodiac, the puppet-head, Stentor - a loss I still mourn - 
Galileus, dancers, the officer), condensed others (Pedro, Peter, and Kepler), and introduced the part of the Narrator (Tyler Nye) to manage scenes in the absence of sets and to signal entrances, exits, and actions to the audience. Frame-breaking within the literal frames of Zoom as our wine-guzzling commentator, crooner, and multiple hat-wearing utility player, Nye kept up the forward motion. This greatest of the liberties we took allowed us to preserve much of the play and focus on the ways that gender, race, and political identity, all of which were actively deployed in the original, might be re-activated for our moment. While we set aside the references to African dancers in Behn's instructions, we talked about James II's role in the Royal African Company and the urgency of not race-blind but race-conscious casting in presenting Restoration and eighteenthcentury work now.

Behn's farce is built on the theme of misperception, with telescopic technology and pseudo-scientific obsession bolstering a culture of political propaganda and conspiracy near the end of James II's troubled reign. We could hardly top Dryden's partisanship in Albion and Albanius, with its final vision of Charles and James triumphant over the body of a poison-oozing Shaftesbury, but Behn's Jacobite sense of disappointment felt strangely familiar. Playing as we did just a few weeks after the 2020 U.S. presidential election, as a defeated Trump flailed about from failed legal challenge to Twitter and back, we couldn't help but notice the parallels, even if we did not see them all in advance. 1687, like 2020 was the final year of a crumbling regime. In an uncertain political future, clouded by conspiracy theories and anxieties about new technologies, what was clear was that an unpopular monarch was about to be forced to leave the palace under conditions that could lead to civil war. Xenophobia and pseudoscience ruled the national discourse, while a corrupt royal family and elites profited from human misery. Dr. Baliardo, obsessed with new visual technologies she believes will let her unlock the mysteries of the universe, is so steeped in this world view that she is ready to conspire with extraterrestrials to overthrow the government and establish her own dynasty in arranging for her daughter and niece to marry moon-men monarchs.

While we had thought through some of the history of the farce in dramaturgical discussions, other things were more immediate discoveries in the reading itself. The absurdities of our present moment only underscored for us how absurdities become possibilities in moments of political crises. The Popish Plot or Q-Anon paranoia about vaccination ought to be the stuff of farce, so perhaps it is only right that farce can limn out how conspiracies become realities in a world turned upside down. Elaine Hobby, in a followup exchange, suggested that Behn's position as a disappointed Tory was much like that of a contemporary Republican Trump supporter, who realizes that her man on the throne had turned out to be a big mistake, and that years of supporting him were yielding not power but embarrassment. As she watched the Stuart monarchy topple, she turned to theatre itself in a prologue and epilogue that plead for the arts and for writers whose pens conquer a world through ideas, with "gentle force" that is equal to, if not greater than, "the useful sword". We couldn't agree more. 
Zoom, imperfect as it is, transported us all who came and to those who were able out of our isolation, erased geographical to put something in the tip jar for the acdistance, and let us remember the joy of tors. They will gratefully use those tips to live theatre during the ghost light time of make rent and buy groceries this winter. pandemic. It was by embracing the painful For those who missed the production and realities and limits of our present moment would like to see the footage, it is available - in the shadow of national conspiracy online (https://tinyurl.com/BehnEmpertheories, a racial reckoning in American orZoom), and for all who would like an intheatre, and our inability to gather in vitation to the next great Zoom adventure physical theatres - that we forged this one- of 2021, sign up at r18collective.org to be off evening and managed to reach an in- on the first-to-know mailing list.

ternational audience. My sincere thanks to 


\section{The Emperor of the Moon: The 11/22/2020 Zoom Table Read}

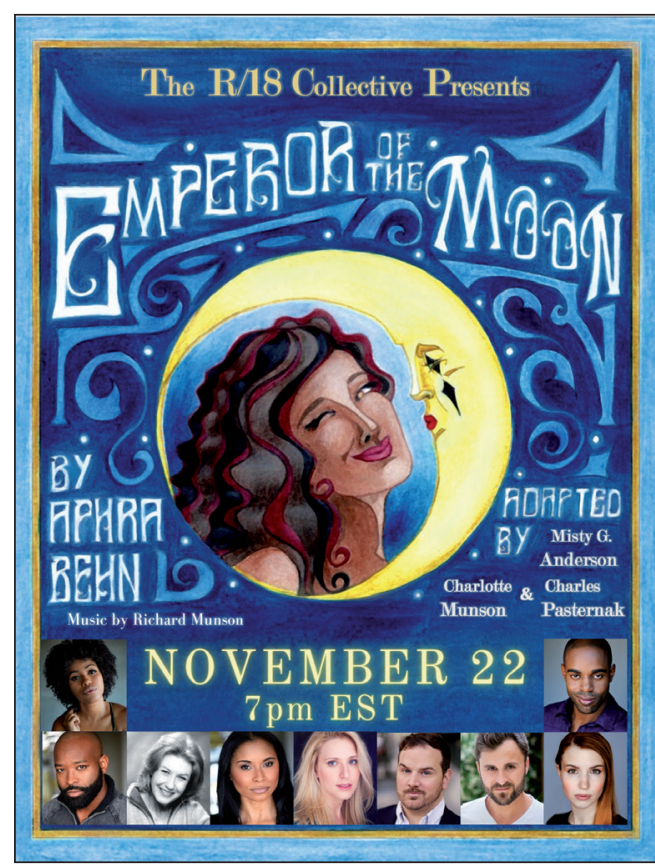

\section{The Cast}

Franceli Chapman as Mopsophil

Gerald Dewey as Don Charmante

Carol Mayo Jenkins as Doctor Baliardo

Swisyzinna Moore as Bellemante

Charlotte Munson as Scaramouch

Tyler Nye as The Narrator

Charles Pasternak as Harlequin

Brittany Pirozzoli as Elaria (\& poster art!)

Chauncy Thomas as Don Cinthio
In order to get to the video... read this

Thank you for your interest in seeing the recording of our table reading of The Emperor of the Moon, by Aphra Behn, produced by the R/18 Collective, script edited by Charlotte Munson, Charles Pasternak, and Misty Anderson. This Zoom reading was conceived in the ghost light time of Covid-19 as a joyful celebration of the archive of $R / 18$ plays and in the hopes of seeing more revivals of its treasures once theatres reopen.

You have permission to enjoy this footage on your own computer or device. You do not have permission to duplicate, stream, or post this video, and you most definitely do not have permission to profit commercially from this footage.

If you want to express your appreciation for being granted access to this footage, please consider putting something in the tip jar at the next R/18Collective Zoom reading. Sign up at r18collective.org

As long as you understand and agree to these restrictions, click here to get to the video!

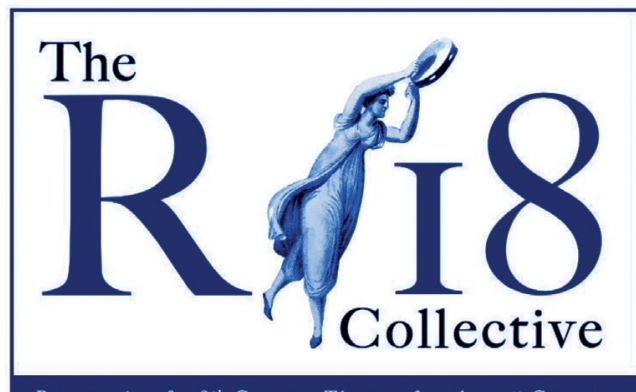

Restoration \& $18^{\text {th }}$-Century Theatre for the $2 I^{\text {st }}$ Century 